\title{
Posição da folha e estádio fenológico do ramo para análise foliar do pinhão-manso
}

\author{
Rosiane. L. S. de Lima ${ }^{1}$, Liv S. Severino ${ }^{2}$, Jairo 0. Cazetta ${ }^{3}$, Carlos A. V. de Azevedo ${ }^{4}$, \\ Valdinei Sofiatti ${ }^{5} \&$ Nair H. C. Arriel ${ }^{5}$
}

\begin{abstract}
RESU MO
A análise foliar é uma ferramenta imprescindível na predição de possíveis desordens nutricionais e avaliação do estádio nutricional das plantas. Este procedimento só é efetivo se a amostragem for feita com padronização da posição da folha no ramo e do tipo de ramo. O bjetivou-se com este trabalho definir a posição da folha no ramo e o tipo de ramo mais apropriado para diagnosticar o estádio nutricional de plantas de pinhão-manso. 0 ensaio consistiu de uma combinação fatorial $(5 \times 2)$, com cinco posições da folha no ramo $\left(1^{\circ}, 2^{\circ}, 3^{\circ}, 5^{\circ}\right.$ e $10^{\circ}$ nós do ramo do ápice para a base) e dois tipos de ramo (vegetativo ou florífero) em delineamento inteiramente casualizado com quatro repetições. Cada amostra de folha foi colhida em 4 ramos secundários de 20 plantas na fase de florescimento. As folhas das posições 2 e 3 são as mais adequadas para análise foliar de N, P, K, S, Cu, Fe, Mn e Zn, pois apresentam valores médios mais estáveis quando comparadas com as demais posições estudadas. As folhas nas posições 5 ou 10 são mais apropriadas para avaliação de Ca e M g. $\mathrm{O}$ estádio fenológico do ramo não influencia os teores de nutrientes, exceto de $\mathrm{Cu}$ e Fe.
\end{abstract}

Palavras-chave: Jatropha curcas L., nutrição mineral, diagnose foliar

\section{Leaf position and phenological stage of branch for leaf analysis of Jatropha plants}

\begin{abstract}
A B STRAC T
Leaf analysis is an important tool for prediction of nutritional disorders and evaluation of nutritional status of plants. This procedure only can be effective if samples are standardized regarding leaf position and phenological stage of the branch. This study had the objective of defining the most appropriate leaf position and type of branch for nutritional diagnosis of Jatropha plants. A factorial combination of five leaf positions $\left(1^{\text {st }}, 2^{\text {nd }}, 3^{\text {rd }}, 5^{\text {th }}\right.$, and $10^{\text {th }}$ node from apex to base) and two types of branch (vegetative and flowering) was adopted in a completely randomized design with four replications. Each leaf sample was collected in 4 secondary branches of 20 plants in the flow ering phase. Leaves in the position 2 and 3 are the most adequate for analyzing $\mathrm{N}, \mathrm{P}, \mathrm{K}, \mathrm{S}, \mathrm{Cu}, \mathrm{Fe}, \mathrm{Mn}$, and $\mathrm{Zn}$, because they present mean values more stable when compared to the other studied positions. Leaves in the position 5 and 10 are more adequate for analyzing $\mathrm{Ca}$ and $\mathrm{Mg}$. The phenological stage of the branch does not influence nutrient content, except of $\mathrm{Cu}$ and Fe.
\end{abstract}

Key words: Jatropha curcas L., mineral nutrition, leaf diagnosis

\footnotetext{
${ }^{1}$ Pesquisadora DCR pela FAPESQ /PB/CN Pq. Rua 0 svaldo Cruz 1143, Centenário, CEP 58428-095, Campina Grande, PB, Fone: (83) 3182-4300. E-mail: limarosiane@yahoo.com.br

2 D outorando em Agronomia pela Texas Tech U niversity, Lubbock, TX, U SA, Embrapa Algodão. Fone: (83)-31824300. E-mail: liv@cnpa.embrapa.br ${ }^{3}$ Departamento de Tecnologia/U N ESP. CEP 14.884-900, Jaboticabal, SP. Email: cazetta@fcav.unesp.br

${ }^{4}$ U AEA. Rua Aprígio Veloso 882, Bodocongó, CEP 58429-140, Campina G rande, PB. Fone: (83) 2101-1056. E-mail: cazevedo@deag.ufcg.edu.br 5 Embrapa Algodão. Rua O svaldo Cruz 1143, Centenário, CEP 58107-720, Campina Grande, PB. Fone: (83) 318243-00. E-mail: vsofiatti@cnpa.embrapa.br; nair@cnpa.embrapa.br
} 


\section{INTRODUÇÃO}

O pinhão-manso (Jatropha curcas L.) é uma espécie perene pertencente à família das Euforbiáceas, de porte arbustivo e crescimento rápido (Lima et al., 2010), originária da América Central mas se encontra vegetando espontaneamente em diversas regiões do Brasil (Lima et al., 2011). Seu cultivo despertou o interesse econômico após a descoberta do alto teor de óleo apresentado em suas sementes (33 a 38\%) o que representa entre 53 e $79 \%$ do peso de seus frutos (Dias et al., 2007) e por se tratar de uma planta rústica adaptada a diversas condições edafoclimáticas (Arruda et al., 2004).

O cultivo racional levanta a necessidade de se determinar o estado nutricional da cultura, com vista ao melhor planejamento e execução das adubações. Para atender a este objetivo a análise foliar é considerada importante ferramenta utilizada na predição de possíveis desordens nutricionais e avaliação do estádio nutricional de plantas (Evans, 1979). Para que os resultados da análise foliar sejam válidos é essencial que todos os fatores que causam variações sobre os teores foliares de nutrientes, sejam identificados. Assim, todas as fontes de variação, como número de folhas e plantas a serem amostradas (Rozane et al., 2007), sazonalidade (Amaral et al., 2002; Lima et al., 2008), idade e posição da folha no ramo (Evans, 1979; Prado \& Natale, 2004; Rodrigues et al., 2010), posição da folha na copa (Amaral et al., 2002; Lima et al., 2007), entre outros fatores, devem ser isoladas (Jones Júnior, 1991).

Dentre os fatores que causam variação dos teores foliares de nutrientes em plantas a posição da folha no ramo tem atraído a atenção de muitos pesquisadores. Koo \& Young (1977) e Maier et al. (1995) recomendam a coleta de folhas localizadas na parte mediana dos ramos de abacateiro (Persea americana Mill) ou da planta ornamental Protea sp. e George et al. (1989) recomendam a coleta de folhas completamente expandidas ou maduras para a cultura da gravioleira (Annona spp). No tecido foliar de plantas de goiabeira, Kumar \& Pandey (1979), constataram que os teores de N, Ca e Mg aumentam da base para o ápice da copa; em contrapartida, os de P, K, Na, Zn e Mn sofrem redução. Assim, os autores recomendaram, de maneira geral, amostrar a $5^{\text {a }}$ folha contada do ápice para a base, a fim de diagnosticar todos os nutrientes. Para a lichieira (Litchi chinensis Sonn.), Kotur \& Sping (1993) aconselharam a utilização do segundo par de folhas a partir do ápice do ramo, em todas as direções e a meia altura da copa das árvores. Para a cultura da Nogueira-pecã (Carya illinoensis (Wang) K. Koch), Cresswell \& Wicson (1986) recomendam a análise nutricional do primeiro par de folhas completamente expandidas, situadas em ramos com menos de $2 \mathrm{~m}$ de altura para diagnosticar o estádio nutricional desta espécie. Por outro lado, Amaral et al. (2002) recomendam a utilização de folhas localizadas nos terços medianos ou basais dos ramos para diagnosticar o estádio nutricional da aceroleira (Malpighia emarginata D.C.).

Destaca-se que a grande maioria dos estudos que envolvem a dinâmica de nutrientes em espécies perenes foi desenvolvida em outros países, o que demonstra a carência de investigações nas condições brasileiras, sobretudo em relação à cultura do pinhão-manso, o qual possui grande potencial de produção de óleo em virtude de encontrar condições edafoclimáticas propícias para o seu desenvolvimento no Brasil.

Desta forma, o trabalho teve como objetivo definir a posição da folha no ramo e o estádio fenológico do ramo, visando à avaliação do estado nutricional da cultura do pinhão-manso.

\section{Material e MÉTOdos}

Este estudo foi realizado no mês de maio de 2009, em plantas de pinhão-manso com 3,5 anos de idade, cultivadas no espaçamento $3 \times 1 \mathrm{~m}$, em uma lavoura comercial situada na Fazenda Estivas, no município de Garanhuns, Estado de Pernambuco, que tem como coordenadas geográficas: $8^{\circ} 56^{\prime}$ $30^{\prime \prime}$ de latitude Sul, $36^{\circ} 27^{\prime}$ '97' de longitude Oeste e $741 \mathrm{~m}$ de altitude. O solo da área de cultivo apresentava $\mathrm{pH}$ (em água) de 6,2; teores trocáveis de $\mathrm{Ca}^{2+}, \mathrm{Mg}^{2+}, \mathrm{Na}^{+}$e K+ $\mathrm{de}$ 25,7; 14,3; 1,47 e $2,3 \mathrm{mmol}_{\mathrm{c}} \mathrm{dm}^{-3}$, respectivamente. A soma de base, a acidez ativa (H+Al) e a CTC, foram de 43,7; 14,0 e de 57,5 mmol $\mathrm{dm}^{-3}$. O teor de $\mathrm{Al}^{3+}$ foi de $0,5 \mathrm{mmol}_{c} \mathrm{dm}^{-3}$, saturação de bases de $76 \%$, teor de $\mathrm{P}$ de $11,4 \mathrm{mg} \mathrm{dm}^{-3}$ e teor de matéria orgânica de $14,7 \mathrm{~g} \mathrm{~kg}^{-1}$, respectivamente.

Estudaram-se os efeitos da coleta de folhas localizadas nas posições 1, 2, 3, 5 e 10, oriundas de ramos secundários, vegetativos e floríferos, objetivando-se a definição da posição da folha no ramo e do estádio fenológico do ramo a ser amostrado. Para a coleta das folhas nas posições estudadas foram consideradas apenas as folhas totalmente expandidas e contadas no sentido ápice/base. Nos ramos contendo flores a contagem das folhas seguiu o mesmo padrão estabelecido para os ramos vegetativos. As plantas estavam visualmente bem nutridas, sem sintomas de deficiência de nutrientes visíveis.

Os tratamentos foram arranjados em esquema fatorial $(5 \mathrm{x}$ $2)$, com cinco posições da folha no ramo $\left(1^{\circ}, 2^{\circ}, 3^{\circ}, 5^{\circ}\right.$ e $10^{\circ}$ nós do ramo, no sentido do ápice para a base da planta) e dois tipos de ramo (vegetativo ou florífero) em delineamento inteiramente casualizado com quatro repetições. As folhas foram colhidas no ramo secundário, no período do florescimento, em quatro ramos por planta, com e sem flor, no total de 20 plantas amostradas.

Após a coleta as folhas foram secadas em estufa de circulação de ar forçada, moídas em moinho tipo Willey e então conduzidas ao Laboratório de Análises de Solo e Nutrição de Plantas da Universidade Estadual Paulista, Campus de Jaboticabal, onde uma porção das amostras trituradas foi submetida a digestão nítrico-perclórica para a determinação das concentrações de P, K, Ca, Mg, S, Cu, Fe, Mn e Zn, enquanto outra foi submetida a digestão sulfúrica visando à determinação do teor de $\mathrm{N}$. O N foi quantificado pelo método colorimétrico de Nessler; o P, pelo método do fosfomolibdato e pela redução da vitamina C, modificado por Braga \& Defelipo (1974), o K por fotometria de chama; o S, por turbidimetria do sulfato de bário (Blanchar et al., 1963), e os demais (Ca, Mg, Cu, Fe, Mn e Zn) foram quantificados por espectrofotometria de absorção atômica em chama.

Os dados obtidos foram submetidos à análise de variância e ao teste F. As diferenças entre os tratamentos foram detectadas pelo teste de Tukey, segundo recomendações de Santos \& Gheyi (2003). 


\section{RESULTADOS E DISCUSSÃO}

A posição da folha no ramo influenciou significativamente os teores de nutrientes no tecido foliar de plantas de pinhãomanso, com exceção do micronutriente $\mathrm{Cu}$. O estádio fenológico do ramo ocasionou diferenças significativas nos nutrientes $\mathrm{N}$, $\mathrm{K}, \mathrm{Ca}, \mathrm{S}$ e Zn (Tabela 1). Houve interação significativa entre os dois fatores estudados; entretanto, apenas para os teores foliares dos micronutrientes $\mathrm{Cu}$ e Fe.

Os teores foliares de $\mathrm{N}$ apresentaram variações significativas em função da posição de coleta da folha constatando-se maiores teores foliares nas folhas colhidas da posição 3 que, por sua vez, não diferiu estatisticamente dos resultados obtidos das folhas da posição 5 (Tabela 2). Por outro lado, observaram-se pequenas diferenças significativas entre os teores obtidos nas folhas de posição 1 e 2, constatando-se que os teores de $\mathrm{N}$ verificados na posição 1 foram levemente superiores aos obtidos na folha 2. Em geral foram observadas pequenas flutuações nos teores foliares deste nutriente não se constando, porém, uma tendência clara em relação ao posicionamento da folha no ramo. Como o nitrogênio é um nutriente de alta mobilidade no floema (Marschner, 2002), essas variações podem ser atribuídas à sua translocação das folhas maduras para as jovens, para as flores e, preferencialmente, para os frutos. Assim, para a predição do estádio nutricional de $\mathrm{N}$ a coleta de folhas em qualquer posição, é valida. Resultados similares foram observados por Pathak \& Pandey (1976) para a cultura da manga. Notou-se diferença significativa nos teores foliares de $\mathrm{N}$ entre ramos frutíferos e vegetativos, sendo as folhas colhidas de ramos vegetativos as que apresentaram maior teor de N; provavelmente, nos ramos frutíferos o $\mathrm{N}$ foi translocado para as estruturas reprodutivas.

Os teores foliares de $\mathrm{P}$ se comportaram de maneira inversa ao N, sendo fortemente influenciados pela posição da folha, com maiores teores na folha de primeira posição da base para $o$ ápice e menores na folha da décima posição (Tabela 2). Valores intermediários foram constatados entre a folha 5 e a folha 10 . Observa-se ainda que os teores foliares de $\mathrm{P}$ decresceram entre as folhas do ápice para a base do ramo cujos resultados sugerem que são necessários estudos mais detalhados sobre a posição de folha no ramo e épocas de amostragem, para se conhecer a variabilidade deste elemento no tecido da planta. Em geral, constatou-se um decréscimo significativo com o avanço da idade da folha tornando-se mais constante a partir da quinta posição. Esses resultados são similares aos constatados por Kumar \& Pandey (1979) para a cultura da goiabeira.

A presença ou ausência de flores no ramo no momento da coleta da folha influenciou os teores de $\mathrm{P}$, semelhante ao verificado com os teores foliares de $\mathrm{N}$, sendo os teores maiores nas folhas colhidas de ramos sem flores. Provavelmente, os teores foliares de $\mathrm{N}$ e $\mathrm{P}$ declinaram significativamente com a emissão de estruturas reprodutivas, visto que esses nutrientes têm alta mobilidade no floema e podem ser retranslocados das folhas maduras para órgãos preferenciais, como folhas jovens, flores e frutos (Marschner, 2002).

Os teores foliares de $\mathrm{K}$ decresceram do ápice para a base até a quinta posição, voltando a aumentar significativamente na posição 10, na qual foi observado o maior teor (Tabela 2). A presença ou ausência de flores nos ramos não influenciou o teor de K (Tabela 2), significando que, para este nutriente, o estádio fenológico do ramo não influencia os resultados da diagnose foliar do pinhão-manso.

Observou-se aumento contínuo nos teores de $\mathrm{Ca}$ foliar do ápice para a base dos ramos (Tabela 2). Aparentemente, este elemento se acumula nas folhas ao longo do tempo e as folhas mais velhas refletem a maior quantidade acumulada. Os teores de Ca medidos nas folhas 1 e 2 não apresentaram diferenças significativas entre si. Os maiores teores foliares de Ca foram constatados na folha 5 e na folha 10 . Resultados similares foram constatados por Kumar \& Pandey (1979) em goiabeiras e por Pathak \& Pandey (1976) em mangueiras. O teor de Ca nas folhas dos ramos floríferos foi menor que nas dos ramos vegetativos,

Tabela 1. Resumo da análise de variância dos teores de macro e micronutrientes medidos em folhas de plantas de pinhão-manso col hidos nas posições $\left(1^{\circ}, 2^{\circ}, 3^{\circ}, 5^{\circ}\right.$ e $\left.10^{\circ}\right)$ de ramos frutíferos e vegetativos

\begin{tabular}{|c|c|c|c|c|c|c|c|c|c|c|c|}
\hline \multirow{2}{*}{ F. V. } & \multirow{2}{*}{ G.L. } & \multicolumn{10}{|c|}{ Quadrados médios } \\
\hline & & N & $\mathbf{P}$ & K & $\mathrm{Ca}$ & $\mathrm{Mg}$ & $\mathbf{S}$ & $\mathrm{Cu}$ & $\mathrm{Fe}$ & $M n$ & $\mathrm{Zn}$ \\
\hline Bloco & 4 & 0,27 & 0,45 & 28,7 & 1,9 & 3,1 & 0,006 & 17,5 & 66,9 & 306,02 & 15,7 \\
\hline Folha (F) & 4 & $2,90 *$ & $6,58^{*}$ & $65,4^{*}$ & $216,0^{*}$ & $104,4^{*}$ & $0,74^{*}$ & 28,9 & $2249,9 *$ & $8811,70 *$ & $646,9 *$ \\
\hline Ramo (R) & 1 & $2,08 *$ & $0,65 *$ & 2,2 & $32,6 *$ & 3,0 & $0,64 *$ & 0,3 & 79,4 & 332,82 & $92,4^{*}$ \\
\hline$F \times R$ & 4 & 0,27 & 0,13 & 36,7 & 0,8 & 5,2 & 0,01 & $43,8^{*}$ & $688,6 *$ & 94,72 & 23,4 \\
\hline Resíduo & 36 & 0,10 & 0,09 & 16,5 & 3,3 & 3,2 & 0,04 & 14,2 & 133,6 & 381,25 & 13,0 \\
\hline CV (\%) & - & 0,76 & 9,70 & 11,8 & 12,6 & 16,8 & 9,30 & 34,1 & 12,9 & 17,2 & 11,6 \\
\hline
\end{tabular}

Tabela 2. Teores foliares de macronutrientes em função da posição da folha no ramo e do estádio fenológico do ramo*

\begin{tabular}{lllllll}
\hline \multicolumn{1}{c}{ Posição da folha } & $\mathbf{N}$ & $\mathbf{P}$ & $\mathbf{K}$ & $\mathbf{C a}$ & $\mathbf{M g}$ & $\mathbf{S}$ \\
Folha 1 & $42,6 \mathrm{bc}$ & $4,1 \mathrm{a}$ & $34,1 \mathrm{ab}$ & $9,3 \mathrm{~d}$ & $7,7 \mathrm{c}$ & $2,5 \mathrm{a}$ \\
Folha 2 & $41,7 \mathrm{~d}$ & $3,6 \mathrm{~b}$ & $33,0 \mathrm{~b}$ & $11,4 \mathrm{~cd}$ & $8,5 \mathrm{c}$ & $2,2 \mathrm{~b}$ \\
Folha 3 & $43,2 \mathrm{a}$ & $2,8 \mathrm{c}$ & $32,9 \mathrm{~b}$ & $13,3 \mathrm{c}$ & $8,9 \mathrm{c}$ & $2,0 \mathrm{bc}$ \\
Folha 5 & $42,8 \mathrm{ab}$ & $2,5 \mathrm{~cd}$ & $32,7 \mathrm{~b}$ & $16,3 \mathrm{~b}$ & $12,4 \mathrm{~b}$ & $2,1 \mathrm{bc}$ \\
Folha 10 & $42,4 \mathrm{c}$ & $2,2 \mathrm{~d}$ & $38,8 \mathrm{a}$ & $21,2 \mathrm{a}$ & $15,4 \mathrm{a}$ & $1,8 \mathrm{c}$ \\
\hline & \multicolumn{7}{c}{ Estádio fenológico do ramo } \\
Ramos Floríferos & $42,4 \mathrm{~b}$ & $2,9 \mathrm{~b}$ & $34,5^{\mathrm{ns}}$ & $15,1 \mathrm{a}$ & $10,8^{\mathrm{ns}}$ & $2,0 \mathrm{~b}$ \\
Ramos Vegetativos & $42,7 \mathrm{a}$ & $3,2 \mathrm{a}$ & $34,1^{\mathrm{ns}}$ & $13,5 \mathrm{~b}$ & $10,4^{\mathrm{ns}}$ & $2,3 \mathrm{a}$ \\
\hline
\end{tabular}

* Médias seguidas pela mesma letra minúscula na coluna não diferem entre si pelo teste de Tukey a 5\% de probabilidade 
Tabela 3. Teores de micronutrientes determinados no tecido foliar de plantas de pinhão-manso colhidos em folhas coletadas das posições $\left(1^{\circ}, 2^{\circ}, 3^{\circ}, 5^{\circ}\right.$ e $\left.10^{\circ}\right)$ de ramos frutíferos (RCF) e vegetativos (RSF)*

\begin{tabular}{|c|c|c|c|c|c|c|}
\hline \multirow{2}{*}{ Posição da folha } & \multicolumn{2}{|c|}{$\mathrm{Cu}$} & \multicolumn{2}{|c|}{$\mathrm{Fe}$} & \multirow{2}{*}{$\mathrm{Mn}$} & \multirow{2}{*}{$\mathrm{Zn}$} \\
\hline & RSF & RCF & RSF & RCF & & \\
\hline Folha 1 & $12,8 \mathrm{Aa}$ & $15,2 \mathrm{Aa}$ & $95,4 \mathrm{Bab}$ & $117,2 \mathrm{Aa}$ & $78,6 \mathrm{~d}$ & $44,0 \mathrm{a}$ \\
\hline Folha 2 & $9,0 \mathrm{Aa}$ & $10,6 \mathrm{Aab}$ & $84,0 \mathrm{Abc}$ & $86,0 \mathrm{Ab}$ & $94,8 \mathrm{~cd}$ & $32,9 \mathrm{~b}$ \\
\hline Folha 3 & $9,4 \mathrm{Aa}$ & $11,2 \mathrm{Aab}$ & $64,6 \mathrm{Ac}$ & $74,0 \mathrm{Ab}$ & 108,8 bc & $28,2 \mathrm{C}$ \\
\hline Folha 5 & 10,4 Aa & $11,4 \mathrm{Aab}$ & $83,2 \mathrm{Abc}$ & $86,2 A b$ & $131,8 a b$ & $25,1 \mathrm{C}$ \\
\hline Folha 10 & $14,0 \mathrm{Aa}$ & $6,4 \mathrm{Bb}$ & $114,2 \mathrm{Aa}$ & $90,6 \mathrm{Bb}$ & $153,5 \mathrm{a}$ & $24,4 \mathrm{C}$ \\
\hline \multicolumn{7}{|c|}{ Estádio fenológico do ramo } \\
\hline Ramo Florífero & - & - & - & - & $116,1^{\mathrm{ns}}$ & $29,6 \mathrm{~b}$ \\
\hline Ramo Vegetativo & - & - & - & - & $110,9^{\text {ns }}$ & $32,3 \mathrm{a}$ \\
\hline
\end{tabular}

* Médias seguidas da mesma letra minúscula na coluna e maiúscula na linha para uma mesma variável não diferem entre si pelo teste de Tukey a $5 \%$ de probabilidade

comportamento oposto ao verificado com os nutrientes $\mathrm{N}$ e P. É possível inferir que tenha ocorrido um direcionamento maior do Ca das folhas para as flores, uma vez que este nutriente tem função estrutural e baixa mobilidade no floema (Leitão \& Silva, 2004).

O magnésio se comporta de maneira similar ao $\mathrm{Ca}$, aumentando o teor do ápice para a base dos ramos; no entanto, não apresentou diferença entre ramos reprodutivos e vegetativos. Apesar do $\mathrm{Mg}$ ser bastante móvel no floema (Marschner, 2002), não se observou redução dos teores foliares devido ao aparecimento das flores, possivelmente porque a demanda por este nutriente não é tão alta nas estruturas reprodutivas quanto para $\mathrm{N}$ e $\mathrm{P}$, sugerindo que a padronização do estádio fenológico do ramo para a coleta da folha diagnóstico não é necessária para avaliar o estádio nutricional quanto a este nutriente.

Os teores foliares de $\mathrm{S}$ decrescem do ápice para a base e são maiores nos ramos sem flores. Semelhantemente ao comportamento exibido pelo $\mathrm{N}$ e pelo $\mathrm{P}, \mathrm{o} \mathrm{S}$ apresentou maiores teores nas folhas colhidas de ramos vegetativos. A faixa de variação dos teores de $\mathrm{S}$ é estreita (entre 1,8 e 2,5 $\mathrm{g} \mathrm{kg}^{-1}$ ), mas é importante a padronização da posição da folha para diagnose foliar do pinhão-manso de vez que a faixa limitante, seja pelo excesso ou pela carência, pode reduzir a produção da planta.

Comumente, os teores de $\mathrm{Ca}$ e $\mathrm{Mg}$ no tecido foliar aumentam com a idade da folha enquanto os teores de $\mathrm{P}$ e $\mathrm{K}$ diminuem sensivelmente. A distribuição do $\mathrm{N}$ não apresentou qualquer tendência oscilando bruscamente entre as posições analisadas.

Quanto aos efeitos da posição da folha e do estádio fenológico do ramo sobre os teores de $\mathrm{Cu}$ e $\mathrm{Fe}$, constatou-se interação entre os dois fatores. Em referência ao Mn e ao Zn, observam-se efeitos isolados apenas do fator posição da folha no ramo (Tabela 3 ).

Os teores de $\mathrm{Cu}$ obtidos no tecido foliar oriundos de ramos frutíferos, colhidos em diferentes posições no ramo, indicaram que os maiores teores deste nutriente ocorreram na folha 1 (15,2 $\left.\mathrm{mg} \mathrm{kg}^{-1}\right)$, não diferindo estatisticamente das demais posições no ramo. Por outro lado, quando se comparam os efeitos da presença ou ausência de flores no ramo verifica-se, para cada posição de folha no ramo, que não houve diferença sobre os teores deste nutriente, com exceção da folha 10 , na qual se constataram teores de $\mathrm{Cu}$ superiores aos daqueles tecidos procedentes de ramos vegetativos.

Quanto ao Fe, o comportamento foi similar ao exibido pelo $\mathrm{Cu}$, ocorrendo apenas flutuações entre os tratamentos estudados; não há tendência para se eleger a posição da folha no ramo ou o tipo de ramo a ser amostrado para amostragem foliar do pinhão-manso para este nutriente.

O Mn tende a se acumular nas folhas mais velhas e não é influenciado pela presença de flores no ramo (Tabela 3 ). A faixa de variação entre posições da folha é ampla (entre 78,6 e 153,5 $\mathrm{mg} \mathrm{kg}^{-1}$ ) e, portanto, este fator deve ser padronizado para a diagnose foliar. $\mathrm{O}$ comportamento foi similar ao $\mathrm{Ca}$ e $\mathrm{Mg}$, nutrientes que se concentram nos tecidos mais velhos; observase este comportamento em elementos com baixa capacidade de redistribuição que passam por um processo de concentração (Pathak \& Pandey, 1976).

Ao contrário dos micronutrientes $\mathrm{Cu}$ e $\mathrm{Fe}$, que possuem mobilidade intermediária no floema, o Mn é considerado um elemento de baixa mobilidade no floema (Marschner, 2002). Esta ressalva é evidente quando se avaliam os efeitos da posição da folha no ramo da planta, ao verificar diferenças significativas entre os tratamentos estudados, devendo-se ressaltar que as folhas mais velhas exibem maior teor foliar de Mn, comparado aos teores constatados nas folhas localizadas nas posições 1 e 2 , respectivamente.

O Zn é um nutriente de mobilidade intermediária no floema porém suas concentrações foram estatisticamente mais elevadas nas folhas mais jovens; este resultado é inesperado, pois tal elemento se acumula, preferencialmente, nos tecidos mais velhos (Marschner, 2002).

Constatou-se que os teores de $\mathrm{Zn}$ nas diferentes localizações das folhas no ramo se encontram muito próximos, diferindo apenas entre as folhas 1 e 2 , sendo iguais entre as folhas 3 e 10 . Os maiores teores deste nutriente foram constatados em folhas colhidas da posição 1 diferindo estatisticamente dos resultados diagnosticados nos tecidos procedentes das posições 2 e 3 , respectivamente.

Observou-se que a instabilidade dos nutrientes nas folhas possivelmente seja atribuída ao contínuo acréscimo ou decréscimo na concentração dos constituintes inorgânicos que variam amplamente da base para o ápice, razão por que as folhas localizadas na porção mediana do ramo seriam as mais indicadas, haja vista que apresentariam valores intermediários.

\section{CONClusões}

1. A posição de coleta de folhas no ramo varia amplamente em função do nutriente. 
2. Para diagnosticar o estádio nutricional de plantas de pinhão-manso quanto a $\mathrm{N}, \mathrm{P}, \mathrm{K}, \mathrm{S}, \mathrm{Cu}, \mathrm{Fe}, \mathrm{Mn}$ e $\mathrm{Zn}$, as folhas colhidas da posição 2 ou 3 são mais adequadas.

3. Para os nutrientes Ca e Mg é mais apropriado amostrar as folhas da base, aquelas localizadas na posição 5 ou 10 .

4. O estádio fenológico do ramo não influencia os teores de nutrientes, exceto o $\mathrm{Cu}$ e o Fe.

\section{Agradecimentos}

Ao convênio BNB/Embrapa pelo apoio financeiro.

\section{LITERATURA CITADA}

Amaral, J. F. T. do.; Bruckner, C. H.; Martinez, H. E. P.; Cruz, C. D.; Godoy, C. L.; Caixeta, S. L. Determination of leaf sampling techniques to assess the nutritional status of Barbados cherry (Malpighia emarginata D.C.). Fruits, v.57, p.161171, 2002.

Arruda, F. P.; Beltrão, N. E. de M.; Andrade, A. P.; Pereira, W. E.; Severino, L. S. Cultivo de pinhão manso (Jatropha curcas L.) como alternativa para o semiárido nordestino. Revista Brasileira de Oleaginosas e Fibrosas, v.8, p.789-799, 2004.

Blanchar, R. W.; Rehm, G.; Caldwell, A. C. Sulfur in plant material by digestion with nitric and perchloric acid. Proceedings of the Soil Science Society of America, Madison, v.29, p.71-72, 1963.

Braga, J. M.; Defelipo, B. V. Determinação espectrofotométrica de $\mathrm{P}$ em extratos de solo e material vegetal. Revista Ceres, v.21, p.73-85, 1974.

Cresswell, G. C.; Wickson, R. J. Seasonal variation in the nutrient composition of the foliage of pecan (Carya illionensis). Australian Journal of Experimental Agriculture, v.26, p.393397, 1986

Dias, L. A. S.; Leme, L. P.; Laviola, B. G; Pallini Filho, A.; Pereira, O. L.; Carvalho, M.; Manfio, C. E.; Santos, A S.; Sousa, L. C. A.; Oliveira, T. S.; Dias, D. C. F. S. Cultivo de pinhão-manso (Jatropha curcas L.) para produção de óleo combustível. Viçosa: Editora UFV, 2007. v.1.40p.

Evans, J. The effects of leaf position and age in foliar analysis of Gmelina arborea. Plant and Soil, v.52, p.547-552, 1979.

George, A. P.; Nissen, R. J.; Carseldine, M. L. Effect of season (vegetative flushing) and leaf position on the leaf nutrient compositon of Annona spp. Hybrid cv. Pink's Mammoth in south-eastern Queensland. Australian Jounal of Experimental Agriculture, v.29, p.587-595, 1989.

Jones Junior, J. B. Plant tissue analysis in micronutrients. In: Mortvedt, J. J.; Cox, F. R.; Welch, L. M. Micronutrients in agriculture. 2.ed. Madison: Soil science Society of America, 1991.p.477-521. Book Series, 4
Koo, R. C. J.; Young, T. W. Effects of age, position, and fruiting status on mineral composition of 'Tonnage' avocado leaves. Journal American Society for Horticultural Science, v.102, p.311-313, 1977.

Kotur, S. C.; Spingh, H. P. Leaf-sampling technique in litchi (Litchi chinensis). Indian Journal of Agricultural Sciences, v.63, p.632-638, 1993.

Kumar, P.; Pandey, R. M. Sampling for mineral content in leaves of guava cultivar 'Lucknow-49'. Scientia Horticulturae, v. 11, n.2, p. 163-174, 1979.

Leitão, A. C.; Silva, O. A. Variação sazonal de macronutrientes em uma espécie arbórea de cerrado, na Reserva Biológica e Estação Experimental de Mogi-Guaçu, estado de São Paulo, Brasil. Rodriguésia, v.55, p.127-136, 2004.

Lima, R. L.; Severino, L. S.; Ferreira, G. B.; Sofiatti, V.; Sampaio, L. R.; Beltrão, N. E. de M. Casca de mamona associada a quatro fontes de matéria orgânica para a produção de mudas de pinhão-manso. Revista Ceres, v.58, p.232-237, 2011.

Lima, R. L.; Severino, L. S.; Pereira, W. E.; Lucena, A. M. A.; Gheyi, H. R.; Arriel, N. H. C. Comprimento das estacas e parte do ramo para formação de mudas de pinhão-manso. Revista Brasileira de Engenharia Agrícola e Ambiental, v.14, p.1234-1239, 2010.

Lima, R. L. S.; Ferreira, G B.; Weber, O. B.; Cazetta, J. O. Diagnose foliar da gravioleira (Annona muricata L.): efeito da posição de ramos e folhas. Ciência e Agrotecnologia, v.31, p.13201325, 2007.

Lima, R. L. S.; Siqueira, D. L.; Ferreira, G B.; Weber, O B.; Cazetta, J. O.; Lopes, F. F. M. Variação sazonal de micronutrientes em folhas de aceroleira (Malpighia emarginata D.C.). Ciência e Agrotecnologia, v.32, p.869-874, 2008.

Maier, N. A.; Barth, G. E.; Cecil, J. S.; Chvyl, W. L.; Bartetzko, M. N. Effect of sampling time and leaf position on leaf nutrient composition of Protea 'Pink ice'. Australian Journal of Experimental Agriculture, v.35, p.275-283, 1995.

Marschner, H. Mineral nutrition of higher plants. London: Academic, 2002. 889p.

Pathar, R. A.; Pandey, R. M. Sampling for mineral content in leaves of mango cultivar 'Dashehari'. Scientia Horticulturae, v.5, p. 255-264, 1976.

Prado, R. M.; Natale, W. Leaf Sampling in carambola trees. Fruits, v.59, p.281-289, 2004.

Rodrigues, M. G. V.; Pacheco, D. D.; Natale, W.; Silva, J. T. A. Amostragem foliar da bananeira 'Prata-Anã'. Revista Brasileira de Fruticultura, v.32, p.321-325, 2010.

Rozane, D. E.; Natale, W.; Prado, R. M.; Barbosa, J. C. Amostragem para diagnose do estado nutricional de mangueiras. Revista Brasileira de Fruticultura, v.29, p.371376, 2007.

Santos, J. W.; Gheyi, H. R. Estatística experimental aplicada. Campina Grande: Editora Gráfica Marcone, 2003. 213p. 